\title{
Metropolização, aglomerações urbano-industriais e desenvolvimento regional no sul do Brasil
}

\author{
Metropolization, urban-industrial agglomerations \\ and regional development in the south of Brazil
}

Paulo Roberto Rodrigues Soares

\section{Resumo}

0 artigo trata das relações entre metropolização, aglomerações urbanas e o desenvolvimento regional. Partindo de uma revisão das tendências contemporâneas da metropolização, busca-se entender como o movimento de reestruturação espacial produtiva repercute nos espaços de urbanização concentrada, especialmente em regiões metropolitanas e aglomerações urbanas. Salientamos que ambos os conceitos são entendidos como formas espaciais, mais além da sua definição institucional. A partir dessta análise, busca-se também entender como espaços em processo de ou vinculados à metropolização podem, com a articulação dos atores regionais, promover políticas de desenvolvimento regional, inclusive com sua conexão com a economia mundializada.

Palavras-chave: metropolização; aglomerações urbanas; mundialização; desenvolvimento regional; Rio Grande do Sul (Brasil).

\begin{abstract}
The article deals with the relations between metropolization, urban agglomerations and regional development. Based on an analysis of the contemporary trends of metropolization, we aim to understand how the movement of productive spatial restructuring reflects on concentrated urban spaces, especially metropolitan areas and urban agglomerations. We highlight that both concepts are understood as spatial forms, beyond their institutional definition. From this analysis, we also aim to understand how spaces in the process of or linked to metropolization can, with the articulation of regional stakeholders, promote regional development policies, including their connection with the global economy.
\end{abstract}

Keywords: metropolization; urban agglomerations; mundialization; regional development; State of Rio Grande do Sul (Brazil). 


\section{Introdução}

No século XXI, o reposicionamento da economia capitalista global, através da continuidade e da ampliação de inúmeros e diversos processos de reestruturação produtiva e espacial, está provocando a emergência de novas aglomerações produtivas, bem como a refuncionalização de aglomerações produtivas tradicionais, especialmente aquelas surgidas durante o período fordista de desenvolvimento, na segunda metade do século XX.

Veltz, em seu clássico trabalho Mundialização, cidades e territórios (1999, p. 9), apontou o que ele considerou os três grandes processos da economia mundial no final do século XX: (1) a mundialização e a globalização da economia; (2) a transformação dos modos de organização e funcionamento das empresas e da produção; e (3) a concentração territorial crescente da economia nas metrópoles acoplada ao crescimento das desigualdades territoriais em todas as escalas.

Desde as décadas finais do século XX, as principais atividades econômicas urbanas, a indústria e os serviços, experimentam novas localizações a partir da generalização, seletiva no território, das condições gerais de produção e da revolução das novas tecnologias de comunicação e informação e da logística, que permitem uma nova autonomia espacial para as unidades produtivas e uma verdadeira transformação em termos de padrões espaciais de localização das atividades de produção, armazenamento de bens, distribuição e consumo.

Essa revolução atinge sobretudo o território das metrópoles, regiões metropolitanas ${ }^{1}$ e aglomerações urbano-industriais - espaços tradicionais de concentração das atividades econômicas na economia capitalista fordista -, as quais enfrentam processos desiguais de reestruturação espacial. Desses processos mais gerais, derivam outros, como a desvalorização e a revalorização dos seus espaços produtivos tradicionais e o rearranjo intraurbano das atividades industriais, comerciais e de serviços. A reestruturação, que se manifesta empiricamente na presença de amplos espaços relegados nas metrópoles, é considerada por muitos como reflexo de uma "crise" desses espaços e da economia metropolitana, já que os mesmos perdem muitos postos de emprego, especialmente no setor secundário. Para nós, esta é uma visão parcial da realidade, pois consideramos essa "crise" como mais um efeito do processo mais amplo de reestruturação do capital, com a extensão da sua fase de reprodução mundializada e financeirizada, a qual inaugura um novo padrão espacial de localização das atividades, que finalmente beneficia as metrópoles com a concentração de funções terciárias, especialmente do terciário superior (também chamado de setor quaternário), isto é, atividades de gestão e comando da economia e do território.

Nesse sentido, o objetivo deste artigo é debater os impactos da reestruturação espacial do capitalismo mundializado nas metrópoles, regiões metropolitanas e aglomerações urbano-industriais, bem como analisar os desdobramentos dessa reestruturação no desenvolvimento produtivo das aglomerações, sobretudo das aglomerações urbanas localizadas nas adjacências de espaços metropolitanos e que, por isso, percebem os rebatimentos do processo de desconcentração da economia metropolitana. 
Para nossa análise, partimos de uma discussão do que é a metropolização e a metrópole na contemporaneidade e de como a nova economia capitalista produz e utiliza-se do espaço metropolitano como suporte de acumulação. A seguir, discutimos o papel e o lugar das aglomerações urbano-industriais no processo de reestruturação espacial do capitalismo, ressaltando a importância desses espaços para o processo de acumulação, especialmente como nova base da economia industrial, mas também com a concentração dos serviços. Finalmente discutiremos qual o papel dessas aglomerações no desenvolvimento regional, considerando seus limites e possibilidades em uma economia mundializada e financeirizada.

Consideramos que as aglomerações urbano-industriais, especialmente as polarizadas por cidades médias, apresentam um papel primordial no desenvolvimento territorial, representando a possibilidade da manutenção de um certo "equilíbrio socioespacial" no desenvolvimento em um período de recrudescimento das polarizações e das desigualdades. Cidades médias, é mister esclarecer, são entendidas, aqui, como cidades não metropolitanas que polarizam redes urbanas regionais e desempenham funções e papéis de gestão intermediária na economia e no território, como aponta Sposito (2007).

Detalharemos nossa posição ao final do artigo. Iniciamos, então, o debate discutindo as tendências contemporâneas da metropolização e suas repercussões no espaço metropolitano.

\section{Pensar a metrópole na contemporaneidade}

Para discutir a metropolização e o desenvolvimento regional, devemos, inicialmente, refletir sobre qual metrópole estamos nos referindo, isto é, pensar o que é a metrópole e a metropolização hoje. $^{2}$

Em uma primeira apreciação, podemos afirmar que esta já não é mais a metrópole industrial fordista tal como conhecemos na segunda metade do século XX e com base na qual foram construídos muitos dos referenciais da teoria urbana nas ciências humanas e sociais. Já naquele momento, e especialmente na década dos anos 1970, iniciou-se a mudança socioeconômica das metrópoles industriais, especialmente nos núcleos metropolitanos, da economia industrial para a economia dos serviços. Então, os serviços passaram a ser mais importantes que a indústria na economia metropolitana como um todo, tanto na composição do seu Produto Interior Bruto (PIB) como na participação da força de trabalho. Inicialmente, esse processo foi mais importante nos núcleos metropolitanos que nas suas periferias, que ainda mantinham os espaços industriais e a concentração do operariado fabril.

Isso ocorreu tanto por motivos de evolução econômica das metrópoles, com o encarecimento dos custos de localização a partir da valorização do solo urbano, como também por qualificação da força de trabalho, crescimento do poder aquisitivo de uma parcela importante 
da população (que demanda serviços), além de mudanças na própria economia capitalista, com um novo padrão de consumo, e também mudanças da indústria com a sua reestruturação e passagem para um padrão pós-fordista de organização.

A indústria reestruturou-se tanto em termos de padrão de produção (com a revolução tecnológica), como nas relações de trabalho (flexibilização, desregulação). 0 que também rebateu nos seus padrões espaciais de localização, com as plantas industriais abandonando os núcleos metropolitanos, primeiramente, rumo aos espaços perimetropolitanos e, posteriormente (e atualmente), buscando os espaços "extrametropolitanos".

A metrópole contemporânea é uma metrópole de serviços, tanto dos serviços pessoais, como dos serviços às empresas. É um espaço funcional para a gestão da economia capitalista mundializada, a qual por sua complexidade exige uma nova e maior racionalidade na gestão por parte das empresas (Sassen, 1998). Recentemente, a economia metropolitana recebe a onda da "economia cultural-cognitiva" ou "criativa", que produz uma nova divisão espacial do trabalho baseada em sistemas de produção flexíveis e uma "geografia intraurbana característica da nova economia" (Scott, 2014, pp. 18-19) onde os espaços de inovação no seu interior vêm gerando processos muitas vezes controversos de "gentrificação" de bairros anteriormente decadentes (ou consolidados e/ou estagnados) e que agora são ocupados pela nova geração de jovens profissionais globalizados, os "hipsters globais".

Além disso, esses novos empreendedores urbanos da era da internet representam uma das pontas de uma forte polarização e dualização do mercado de trabalho metropolitano: atividades de alta especialização de caráter global convivendo e se sobrepondo a serviços básicos que solicitam mão de obra de baixa qualificação e de caráter local. Enquanto as categorias médias, mais vinculadas ao regional e ao nacional, muitas vezes quadros médios do próprio Estado, estão sendo comprimidas e diminuindo sua participação na pirâmide social.

Essas transformações na economia metropolitana têm também rebatimentos da produção espacial da metrópole com a produção de novas centralidades e de novos espaços de valorização e mudanças importantes no mercado imobiliário metropolitano. Nosso propósito, no entanto, não é discutir detalhadamente essa questão neste artigo.

Mas o importante também é entender que as regiões metropolitanas estão muito mais complexas que antes, com novas centralidades e novas periferias metropolitanas, como veremos a seguir.

\section{0 que é a metropolização hoje?}

A metrópole transforma-se porque na contemporaneidade o processo de metropolização também está passando por uma grande transformação. Atualmente falamos em uma metropolização estendida, em uma metrópole dispersa, extensa, com bordas e limites cada vez mais remotos, difusos e imprecisos.

Nesse sentido, a metropolização implica uma série de processos mais amplos, entre eles os de concentração, dos capitais, da população, dos bens materiais e imateriais, da decisão, da gestão e da informação; de "seleção dos lugares", na atração de empresas e 
de trabalhadores altamente qualificados; de difusão ou de expansão da metropolização, ou a chamada "metropolização do espaço" e, como consequência dos anteriores, de dualização, com o aumento das desigualdades territoriais entre os territórios metropolitanos e/ou "metropolizados", e os territórios não integrados ou excluídos da metropolização (Leroy, 2000). Assim, a metropolização é muito mais que "um simples fenômeno de crescimento das grandes aglomerações"; é um processo que implica também mudanças significativas no funcionamento cotidiano das aglomerações e o engendramento de novos tipos de morfologias urbanas (Ascher, 1998, apud ibid., p. 80).

Esses mesmos processos (concentração, seleção, dualização) podem ser considerados tanto "internamente" à metrópole, como na relação desta com os espaços extrametropolitanos na escala urbano-regional. A metropolização do território, como denomina Font (2007, apud Montejano Escamilla, 2013):

puede resumirse como la aparición o potenciación de dinámicas de carácter urbano y de su difusión por los diversos territorios, que van integrándose funcional y económicamente y que van asumiendo progresivamente características metropolitanas en cuanto al uso del espacio, consumo del suelo y energía, estructuración funcional, movilidad pluridireccional, existencia de polaridades especializadas, uso intensivo de los espacios "naturales", emergencia de nuevas morfologías, etc. (p. 40)

A geógrafa Sandra Lencioni considera que o processo de "metropolização do espaço" incorpora algumas características do processo de urbanização e desenvolve novas. Entre elas, temos a grande intensidade de fluxos de pessoas, mercadorias e capitais; o crescimento das atividades de serviços, especialmente os superiores; a demanda cada vez maior de trabalho imaterial; a concentração de atividades de gestão e controle; a maior utilização de tecnologias de informação e comunicação; a grande variedade de atividades econômicas; a exacerbação da associação entre o capital financeiro, promotores imobiliários e indústria da construção; a produção de um modo de viver e de consumo que se espelha no perfil da metrópole (Lencioni, 2013).

Trata-se, portanto, de "uma nova fase histórica da urbanização" (Lencioni, 2005, 2011, 2013), a qual também comporta algumas mudanças importantes como: a formação de uma região urbana com ampla escala territorial; a constituição de espaços homogêneos, hierarquizados, fragmentados e segregados; a redefinição das hierarquias urbanas intra e inter-regionais; a intensidade e diversidade dos fluxos materiais e imateriais intrametropolitanos e entre a metrópole e outras regiões urbanas.

A metropolização do espaço, portanto, não se restringe às regiões metropolitanas, já que incorpora cidades médias, cidades pequenas e o "mundo" rural, hoje transformado e incorporando urbanidades (o rururbano?). Já se passaram duas décadas desde a formulação do conceito de "metápolis" por Ascher (1995), quando este definiu o "novo território urbano" como

um conjunto de espaços onde todos ou parte dos habitantes, das atividades econômicas ou dos territórios são integrados ao funcionamento cotidiano (ordinário) de uma metrópole. Uma metápole constitui geralmente, uma "bacia 
de empregos", de habitat e de atividades. Os espaços que compõem a metápole são profundamente heterogêneos e não necessariamente contíguos. (p. 34)

A partir de então, uma série de conceituações apontou para o que o urbanista De Mattos (2014) chama de "metamorfose urbana" ou, parafraseando Lefebvre (1972), de uma autêntica "revolução urbana" com a constituição de regiões metropolitanas "estendidas, multinodais e multicêntricas" (Brenner, 2002). Cacciari (2010) considera que as metrópoles "já não estruturam o espaço", pois cederam lugar a uma nova forma espacial, chamada por ele de "cidade-território" ou "um espaço indefinido, homogêneo e indiferente em seus lugares". Todas essas características estão contempladas no espaço designado por Soja (2000) como a "pós-metrópole", ou seja, a forma urbana que ultrapassa a metrópole fordista moderna, mas não a faz desaparecer completamente.

Todo esse conjunto de novos conceitos ou neologismos (entre tantos outros que poderíamos enumerar) ${ }^{3}$ já aponta para a ideia de que mutações importantes estão acontecendo nas metrópoles e nos espaços urbanos contemporâneos.

Assim, um primeiro problema que se coloca no estudo do desenvolvimento territorial de um determinado espaço é o da delimitação do âmbito espacial real da dinâmica territorial que estamos abordando, estabelecendo quais espaços integram esse âmbito e que nos permitem falar de "área metropolitana", "região metropolitana", "região funcional urbana", etc.

Como no Brasil (e no Rio Grande do Sul) temos as delimitações oficiais do que é região metropolitana ou aglomeração urbana e, mesmo, microrregião, somos tentados muitas vezes a circunscrever os fenômenos que estamos analisando a esse âmbito territorial administrativo "institucional". ${ }^{4}$ Este não é o caminho que vamos seguir aqui. Concordando com Silveira (2010, p. 70), em termos de regionalização (e a instituição de regiões metropolitanas e/ou aglomerações urbanas é uma regionalização), nosso interesse em definir limites é menor que o empenho em abordar processos. Ainda mais se admitimos que, em uma sociedade onde os processos sociais e econômicos cada vez mais se constituem sob uma lógica reticular, a forma metropolitana, além de dispersa, pode ser descontínua, ou seja, pode contemplar espaços integrados à metropolização, mas não necessariamente contíguos ou contínuos ao espaço metropolitano. De igual forma, coloca-se a questão da escala de análise, pois estamos diante de uma questão que envolve múltiplas escalas e níveis de análise que se justapõem e se entrelaçam: da escala global, passando pela nacional, pela regional, chegando à local; do interurbano, ao intraurbano, passando pelo urbano-regional. ${ }^{5}$

Nesse sentido, ao nos referirmos à "região" metropolitana, estamos nos referindo a um espaço metropolizado que às vezes se ajusta e, em muitas outras, não coincide com os limites metropolitanos oficiais. Os processos econômicos e sociais de que estamos tratando envolvem tempos muito distintos, por mais velozes, que os da política regional oficial, ao mesmo tempo que esta tem dificuldades de responder e incorporar, ao arcabouço legal, conceitos e análises do âmbito socioespacial produzidos pela academia. Entretanto, como já apontado, consideramos mais importante discutir os processos a partir das mudanças no 
núcleo e nas periferias metropolitanas e suas relações e impactos nos espaços adjacentes e exteriores à metrópole.

As transformações no sistema produtivo, nos meios de transporte de bens, pessoas e informações e especialmente nas (tele)comunicações, nas relações sociais e de trabalho, que caracterizam a sociedade contemporânea, produziram mudanças na estruturação territorial, redefinindo espaços de inter-relação cotidiana e de funcionamento econômico e territorial sensivelmente mais amplos que os habituais da segunda metade do século $X X$.

A já referida "metápole", a cidade-região e a região funcional urbana, produtos do processo de urbanização regional (Soja, 2013), representam a superação qualitativa dos tradicionais conceitos de "área" e "região" metropolitana, em que o caráter monocêntrico destas é fortemente impactado pela incorporação de novos centros, aglomerações urbanas, cidades médias, áreas urbanas dispersas que passam a se integrar em conjuntos espaciais com inter-relações sociais e econômicas significativas. Como evidencia Soja,

a metrópole monocêntrica moderna se metamorfoseia em uma cidade regional policêntrica, abrangendo uma rede amplamente distribuída de aglomerações de variados tamanhos - uma nova geografia urbana. (Ibid., p. 154)

0 mesmo autor explica o processo de urbanização regional, o qual "se desdobra em várias escalas diferentes" e atinge uma esfera planetária:

A extensão dos efeitos da urbanização regional se traduziu numa expansão em escala bem além dos antigos limites do entorno da metrópole moderna. A urbanização metropolitana ocupou uma escala singular, entre 0 urbano ou municipal e a escala regional subnacional. A urbanização regional não somente pode ser definida em múltiplas escalas do local ao global; pode-se também argumentar de forma persuasiva que uma peculiar convergência escalar vem ocorrendo no crescimento de cidades-região ou cidades regionais. As escalas urbana, metropolitana e regional subnacional parecem estar se amalgamando em muitas partes do mundo, resultando no surgimento de "redes regionais de aglomerações". (Ibid., pp. 157-158)

0 processo de urbanização regional redunda na constituição de novos âmbitos espaciais nos quais as relações econômicas e sociais se realizam e se concentram. Esses novos âmbitos abrangem as regiões metropolitanas fordistas tradicionais, impactadas e convertidas pela nova economia capitalista em regiões "pós-metropolitanas", concentradoras de serviços e de algumas aglomerações industriais, as quais, em um cenário de dispersão e de difusão urbana, incorporam ao seu âmbito de funcional, não só novos espaços metropolizados, como também aglomerações urbanas, cidades médias, cidades pequenas e espaços "rururbanos" modernizados, com intensos fluxos e relações, em múltiplos sentidos e em rede.

Dois desses âmbitos espaciais podem ser mais bem definidos aqui: as "cidades-regiões" e as "regiões funcionais urbanas".

0 conceito de cidade-região não é recente, foi desenvolvido pelo urbanista escocês Patrick Geddes na segunda década do século XX (1915). Referia-se às concentrações urbanas e industriais da Inglaterra que estavam 
assumindo um funcionamento de caráter regional e descentralizado. Ao final do século $X X, 0$ conceito foi resgatado pela concepção das "cidades-regiões globais" (Scott et al. 2001), entendidas como as novas regiões polarizadoras da economia mundial, que concentram uma ou mais metrópoles, regiões metropolitanas, aglomerações urbanas, cidades médias, em um conjunto espacial único de funcionamento em rede e - importante - conectado à economia global, seja à economia industrial, com produtos ou cadeias de produção globais, seja ao centro de serviços (especialmente financeiros) que as conectam diretamente com as cidades mundiais. Embora a elaboração dos pesquisadores estadunidenses seja interessante, consideramos a definição de cidade-região de Pradilla-Cobos e Márquez López (2007; publicado originalmente em 1998) como uma das mais completas e detalhadas sobre esses novos espaços que são definidos como

um grande sistema urbano uni ou multicêntrico, com uma trama densa, mas não necessariamente contínua, de suportes materiais de infraestruturas e serviços, habitações, atividades econômicas, políticas, culturais, administrativas e de gestão, resultante da expansão centrífuga de uma ou várias cidades ou metrópoles próximas, que articula e/ou absorve a outros assentamentos humanos em sua periferia ou ao largo das vias de transporte que os unem $\mathrm{a}$ áreas rurais intersticiais; esse conjunto está integrado como um todo único, porém contraditório, por uma alta intensidade de relações e fluxos permanentes de mercadorias, pessoas, capitais, mensagens e informações; nessa trama, a localização de atividades é relativamente indiferente, na medida em que seus lugares compartiIham os efeitos úteis de aglomeração e as vantagens comparativas. (p. 263)
Nesse sentido, essa definição aproxima e relaciona os processos da urbanização latino-americana nessa última fase do padrão de acumulação de capital, mundializado e financeirizado, com os processos mais amplos e globalizadores presentes em outras economias do capitalismo avançado mundial.

Quanto às "regiões funcionais urbanas", Serrano Rodríguez (2003) também destaca o papel das novas centralidades na sua constituição:

el carácter monocéntrico de las áreas metropolitanas (polarizadas en un único municipio central, origen de la formación del área metropolitana) se ve fuertemente matizado por la incorporación de nuevos centros - de similar o inferior relevancia, orígenes a su vez del establecimiento de áreas metropolitanas o de áreas urbanas -, que pasan a integrarse en el conjunto de la región funcional urbana. (p. 39)

As novas regiões urbanas possuem três características fundamentais (ibid.):

1) são polinucleares: com múltiplos centros articulados em diferentes níveis e funções. Entre eles, os centros históricos e administrativos metropolitanos tradicionais, os novos centros especializados, os centros financeiros voltados para a economia global e regional (hinterlândia), os centros metropolitanos secundários e as novas centralidades, assentadas em espaços que não constituíam centralidades em períodos anteriores (shopping centers, centros empresariais, campi universitários, centros hospitalares, centros de convenções, aeroportos, arenas esportivas) e que hoje concentram funções, comércio e serviços mais além de sua função tradicional; 
2) são polifuncionais: com comércio, serviços tradicionais, serviços avançados, indústrias tradicionais, indústrias modernas, indústrias de alta tecnologia, serviços de educação, saúde, cultura e lazer, turismo e produção agrícola alternativa para o consumidor urbano (orgânicos, produtos "da terra"), sem esquecer das atividades do circuito inferior da economia urbana, tanto comerciais e de serviços, como industriais, as quais predominam nos setores de habitação das classes populares no centro e na periferia metropolitana;

3) têm um potencial de desenvolvimento autônomo do território, tanto do território regional, como do nacional, podendo estar mais integradas a uma economia em rede global, que ao seu entorno territorial tradicional. Mas essa condição não impede que também continuem centralizando a economia regional, constituindo-se como plataforma para sua inserção na economia global.

Contudo, nossa sociedade, que já foi (a nosso ver equivocadamente) chamada de pós-industrial, não prescinde da indústria, pelo contrário, cada vez mais os produtos industriais estão imbricados em nossa vida cotidiana. Então, se a indústria já não está nos espaços que tradicionalmente ocupava, ela assume novas lógicas de localização e está em algum lugar, seja em outros países ou continentes, como é o caso da China e do Sudeste Asiático, seja nas cidades médias e pequenas do interior do território. A questão é que, ao nos debruçarmos sobre os dados de predominância da indústria ou dos serviços no PIB, verificamos, a partir de um padrão estatístico de um referencial tecnológico de períodos anteriores, a reestruturação tecnológica do capital industrial e o desenvolvimento da economia informacional e dos serviços. Enquanto indústria (e a moderna agricultura), avançam em conteúdo tecnológico e reduzem a utilização de força de trabalho, os serviços se desenvolvem como setor e são intrincados nos outros setores (a própria indústria e a agricultura), ampliando assim, significativamente, sua "fatia" na distribuição da mão de obra entre os setores da economia.

Evidentemente, a grande indústria não está mais nas metrópoles, mas a indústria ainda está em algum lugar. E esse lugar são as aglomerações urbano-industriais, especialmente as polarizadas por cidades médias.

\section{Metropolização e aglomerações urbano-industriais}

Está significativamente constatado que o processo de globalização da economia se associaà reestruturação produtiva e à reorganização territorial, com a criação de novos espaços industriais em distintas escalas territoriais (Soja, 2005). Tal como colocamos anteriormente, difundem-se formas avançadas de industrialização e condições de produção e metropolização características das sociedades urbanas avançadas por espaços nos quais estas estavam pouco presentes em décadas anteriores.

0 urbanista italiano Indovina (2007) destacou, como características desses novos espaços, uma tendência à distribuição do potencial produtivo por localizações "exurbanas", aliada a uma distribuição de numerosos polos especializados pelo território, o que leva à emergência de "fluxos pluridirecionais" e à aparição de uma mobilidade espacial multidirecional, com 
tendências a dispersão e redensificação dos espaços urbanos. E afirma que "o novo mosaico da metropolização se caracteriza pela integração em um contexto de dispersão" (p. 22).

Configura-se, assim, um novo desenho para a rede urbana, com a subversão da tradicional hierarquia urbana, emergindo novas formas de concentração - diferenciadas e mais complexas - que se sobrepõem e extrapolam a clássica rede urbana polarizada pela região metropolitana industrial fordista.

Serviços e indústria desconcentram-se, em um movimento assim explicado por Méndez (2010, p. 143):

En primer lugar, el aumento del nivel de renta y consumo de buena parte de la población urbana permite que determinados comercios y servicios que antes no alcanzaban aquí un umbral de demanda suficiente sí lo encuentren ahora, en tanto las empresas industriales operan ya de forma generalizada para mercados amplios, lo que elimina la influencia del consumo local. A su vez, en una economia cada vez más segmentada, algunas tareas antes concentradas en un mismo establecimiento dentro de las grandes ciudades encuentran ahora mejores condiciones deslocalizarse en ciudades de menores costes, pero bien conectadas, lo que permite atraer hacia ellas algunos establecimientos de empresas red que fragmentan espacialmente su actividad.

A dispersão da indústria a traslada para as cidades médias, especialmente as mais bem localizadas (do ponto de vista do capital) no território, o que significa que possuem ligações rápidas e eficientes com as metrópoles. Também, dentro da perspectiva da "seletividade dos lugares", busca aquelas cidades que já possuíam alguma "tradição" industrial, das quais se aproveitará do ambiente cultural e institucional para sua implantação. Por isso, a dispersão da indústria reforça a posição de determinadas cidades médias no cenário territorial.

Ao se reindustrializarem, com base em um paradigma industrial pós-fordista, as cidades médias passam por processos semelhantes ao das metrópoles conformando novas aglomerações. É o que chamamos de "aglomerações urbano-industriais", concentrações urbanas de porte médio e de caráter intermediário na hierarquia urbana, que reforçam sua posição como centros industriais e de serviços, especialmente se albergam "sistemas locais de produção", ou concentrações industriais ligadas a "cadeias globais de produção".

Benko e Lipietz (1994) chamaram essas aglomerações de "regiões ganhadoras". Se observarmos os casos apresentados no clássico livro, a grande maioria deles se refere a aglomerações deste tipo: cidades de porte médio, intermediárias na hierarquia urbana, com médias e pequenas cidades no seu entorno e que formam uma concentração urbana relativamente densa. Concentram indústrias vinculadas a sistemas produtivos locais especializados, que estão conectadas à economia global e crescem em serviços por conta das necessidades dessa economia industrial (serviços às empresas) e da população que ela concentra (serviços para as pessoas), especialmente para as classes médias que se ampliam nessas aglomerações, uma vez que a economia industrial e os serviços às empresas requerem mão de obra qualificada.

No Brasil, temos vários exemplos dessas aglomerações, especialmente na chamada "região concentrada" delineada por de Santos (1993) ou no "polígono industrial" se 
preferirmos a delimitação de Campolina-Diniz e Crocco (1996). Nos estados da região Sul (Paraná, Santa Catarina), nos quais a indústria tem importante participação na composição do PIB (24,5\% e $33,7 \%$, respectivamente segundo o IBGE, 2014), temos numerosos exemplos. ${ }^{6}$

No próprio Rio Grande do Sul, com 25,2\% de participação no PIB (ibid.), a indústria é um fenômeno presente em diversas regiões e aglomerações pelo interior do estado que possuem importantes concentrações industriais: Caxias do Sul, Bento Gonçalves, Farroupilha, Carlos Barbosa-Garibaldi, Pelotas-Rio Grande, Lajeado-Estrela-Teutônia, Novo Hamburgo-Vale do Sinos, Vale do Paranhana, Passo Fundo-Marau e, evidentemente, Santa Cruz do Sul-Veracruz-Venâncio Aires. Poderíamos ainda acrescentar "aglomerações" de caráter disperso, como os casos de Santa Rosa, Horizontina, Panambi, Ijuí e Erechim.
Estudo recente da Fundação de Economia e Estatística (FEE-RS) apontou a presença de 99 aglomerações produtivas com características de arranjos produtivos locais (APLs), a grande maioria delas concentrada nas aglomerações metropolitanas e urbanas mais importantes do estado, destacando-se, além da região metropolitana de Porto Alegre (22 APLs), a região metropolitana da Serra Gaúcha (14) e as aglomerações de Lajeado-Estrela (7), Passo Fundo (5) e Santa Cruz do Sul, com 4 APLs (Guerrero e Conceição, 2011).

0 Quadro 1 demonstra como a indústria ainda é presente no PIB das aglomerações gaúchas, a maioria delas (com exceção da aglomeração urbana do Sul) com participação do setor secundário no PIB maior que a média do estado e até mesmo que a própria região metropolitana de Porto Alegre. ${ }^{7}$

\section{Quadro 1 - RS: Regiões metropolitanas e aglomerações urbanas - características do PIB*}

\begin{tabular}{|l|c|c|c|}
\hline \multicolumn{1}{|c|}{ Aglomeração } & \% PIB do Estado & \% PIB Industrial & \% da Indústria no PIB \\
\hline RMPA & 42,08 & 43,15 & 23,97 \\
RMPA (- PoA) & 24,02 & 33,42 & 32,29 \\
RMSG & 10,19 & 16,31 & 37,40 \\
AUSUL & 4,14 & 3,66 & 20,69 \\
SCS-VA & 3,19 & 4,71 & 34,54 \\
Lajeado-Estrela & 1,93 & 2,70 & 32,78 \\
\hline Total & 60,90 & 70,53 & 23,38 (RS) \\
\hline
\end{tabular}

*Dados referentes ao PIB municipal de 2014, publicados em 2016.

Fonte: IBGE e FEE. Organização: o autor em 2017. 
Se observarmos os vinte municípios gaúchos com maior participação no PIB industrial do estado verificaremos que a grande maioria se localiza em alguma das aglomerações, como demonstra o Quadro 2.

Um traço comum à maioria dessas aglomerações é a sua forte e intensa relação com a metrópole.

A metrópole é indispensável às aglomerações urbano-industriais, assim como as aglomerações são imprescindíveis para as metrópoles. A concentração de atividades do terciário superior (finanças, gestão, controle e informação) na metrópole responde tanto às necessidades de comando das atividades econômicas metropolitanas como das atividades presentes nas aglomerações. 0 que queremos afirmar é que parcela importante da economia industrial do Rio Grande do Sul, especialmente a mais dinâmica, tem na metrópole o seu

Quadro 2 - RS: os 20 maiores municípios em participação no PIB Industrial do estado

\begin{tabular}{|c|c|c|c|c|c|}
\hline \multirow{2}{*}{ Município } & \multirow{2}{*}{ Aglomeração } & \multicolumn{3}{|c|}{ Estrutura do VAB (\%) } & \multirow{2}{*}{$\%$ da Indústria } \\
\hline & & A & I & S & \\
\hline Caxias do Sul & RMSG & 1,24 & 37,57 & 61,19 & 9,76 \\
\hline Porto Alegre & RMPA & 0,04 & 12,90 & 87,06 & 9,73 \\
\hline Gravataí & RMPA & 0,15 & 49,28 & 50,57 & 5,87 \\
\hline Triunfo & RMPA & 1,36 & 77,03 & 21,61 & 4,69 \\
\hline Santa Cruz do Sul & SCS-VA & 2,56 & 35,63 & 61,81 & 2,93 \\
\hline Bento Gonçalves & RMSG & 1,52 & 39,78 & 58,71 & 2,47 \\
\hline Novo Hamburgo & RMPA & 0,24 & 25,38 & 74,38 & 2,39 \\
\hline Rio Grande & AUSUL & 2,62 & 27,69 & 69,69 & 2,37 \\
\hline São Leopoldo & RMPA & 0,05 & 28,30 & 71,65 & 2,26 \\
\hline Erechim & - & 1,48 & 37,63 & 60,89 & 1,86 \\
\hline Venâncio Aires & SCS-VA & 7,74 & 45,90 & 46,36 & 1,58 \\
\hline Cachoeirinha & RMPA & 0,02 & 29,45 & 70,53 & 1,56 \\
\hline Passo Fundo & - & 1,98 & 16,43 & 81,59 & 1,47 \\
\hline Montenegro & RMPA & 2,31 & 44,75 & 52,95 & 1,45 \\
\hline Sapucaia do Sul & RMPA & 0,15 & 38,71 & 61,15 & 1,37 \\
\hline Sapiranga & RMPA & 0,19 & 43,89 & 55,92 & 1,35 \\
\hline Guaíba & RMPA & 0,97 & 27,68 & 71,35 & 1,33 \\
\hline Horizontina & - & 3,33 & 60,41 & 36,26 & 1,26 \\
\hline Farroupilha & RMSG & 5,15 & 36,24 & 58,61 & 1,11 \\
\hline Canoas & RMPA & 0,06 & 9,97 & 89,97 & 1,09 \\
\hline
\end{tabular}

Dados referentes ao PIB municipal de 2014, publicados em 2016.

Fonte: IBGE e FEE. Organização: o autor em 2017. 
suporte para inserção em um mercado global, ao mesmo tempo que a presença dessas aglomerações no interior do estado contribui para 0 crescimento do terciário superior na metrópole.

Nesse sentido, ao longo dessas duas primeiras décadas do século XXI, a metrópole de Porto Alegre produziu uma nova centralidade do terciário superior que concentra atividades de gestão da economia capitalista adequadas para a inserção da economia regional na economia globalizada. A avenida Carlos Gomes (Terceira Perimetral) e seu entorno concentram sedes de empresas, centros empresariais, empresas financeiras, de consultoria, entre outras (Soares e Flores, 2016). Além disso, a presença de hotéis de categoria internacional nessa avenida e no bairro Moinhos de Vento, conforma esse setor da metrópole como uma nova centralidade da economia metropolitana. Adicione-se, a essas condições, a presença do aeroporto internacional, imprescindível para a conexão de executivos e consultores e para as relações face to face.

0 mesmo acontece quando nos referimos ao mercado de trabalho metropolitano e à economia metropolitana tendo como referência somente a região metropolitana de Porto Alegre. Hoje em dia essa economia e esse mercado de trabalho têm relações inseparáveis com a economia do Rio Grande do Sul, especialmente com as aglomerações industriais do entorno metropolitano, as quais demandam serviços avançados à metrópole. Esses serviços são importantíssimos para o desenvolvimento da indústria nas aglomerações, que, mesmo que desenvolvam algumas atividades do setor terciário superior, ele não tem a complexidade e a densidade do terciário avançado presente na metrópole.
Assim, retomando as ideias anteriores, podemos dizer que a metrópole, a região metropolitana e as aglomerações urbano-industriais do entorno metropolitano fazem parte de um conjunto espacial ou de uma nova forma espacial que pode ser considerada a "cidade-região" ou a "região urbana" de Porto Alegre.

Esta é formada pela região metropolitana, mais as aglomerações urbanas no entorno, como a da Serra Gaúcha, Lajeado-Estrela, Santa Cruz do Sul, Litoral Norte, Gramado-Canela e Taquara-Parobé-Igrejinha, com grande densidade de fluxos e intensidade de relações com a metrópole, além de concentrar mais de $60 \%$ PIB, cerca de $70 \%$ do PIB industrial e mais de $50 \%$ da população do estado (Soares e Schneider, 2012). A Figura 1 ilustra essa região urbana.

Pelo que observamos na Figura 1, em um raio de cerca de $100 \mathrm{~km}$ de Porto Alegre, estão se desenvolvendo diversos processos urbanos de aglomeração, concentração e conurbação, configurando uma urbanização simultaneamente dispersa e fragmentada, com diferentes núcleos polarizadores. Os fluxos populacionais e econômicos nesse entorno são complexos e multidirecionais, tendo, entretanto, como núcleo principal a metrópole de Porto Alegre.

A Figura 1 pode ser cotejada com a Figura 2 que representa os fluxos da rede urbana do entorno de Porto Alegre, conforme o estudo de "Regiões de Influência das Cidades" do IBGE (2008). Pela Figura 2, percebemos os intensos fluxos entre esses centros urbanos do entorno, bem como o papel dos principais centros (Caxias do Sul, Novo Hamburgo, Santa Cruz do Sul, Lajeado, Bento Gonçalves) como polarizadores de redes urbanas de caráter sub-regional. 
Figura 1 - Arranjos populacionais e contrações urbanas no entorno de Porto Alegre

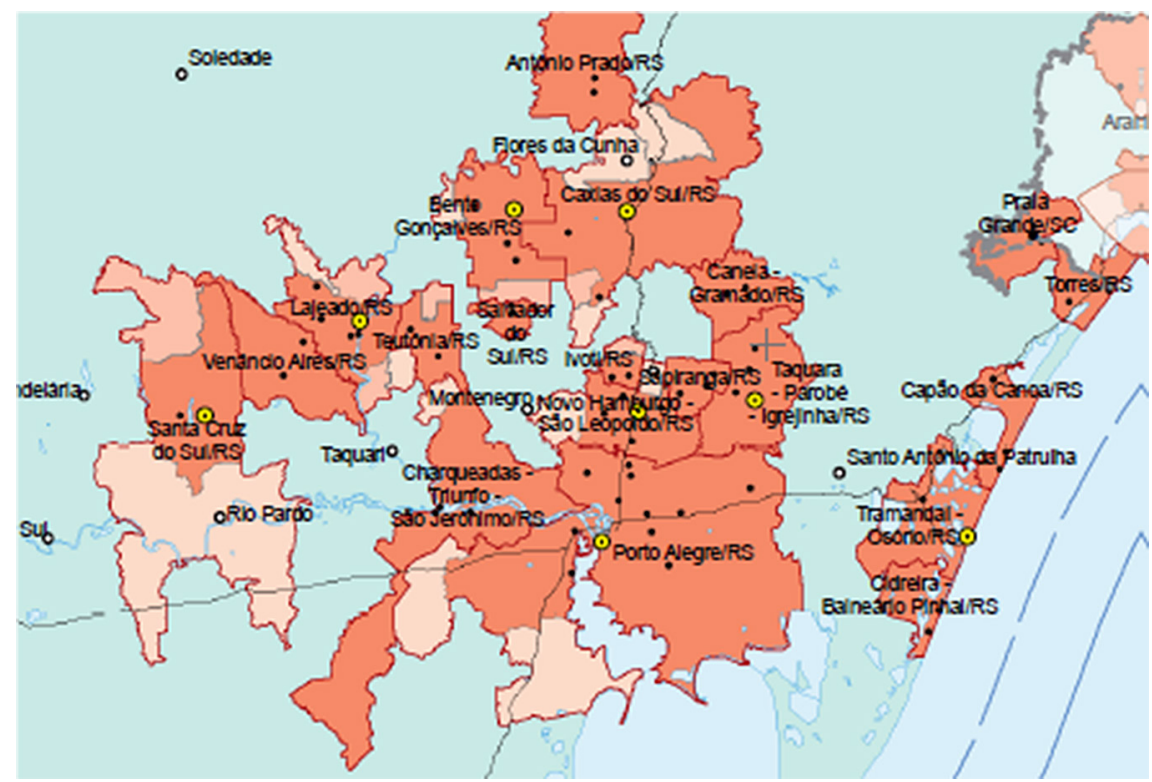

Fonte: adaptado de IBGE (2015, p. 143).

Figura 2 - Fluxos de polarização no entorno de Porto Alegre segundo a Regic

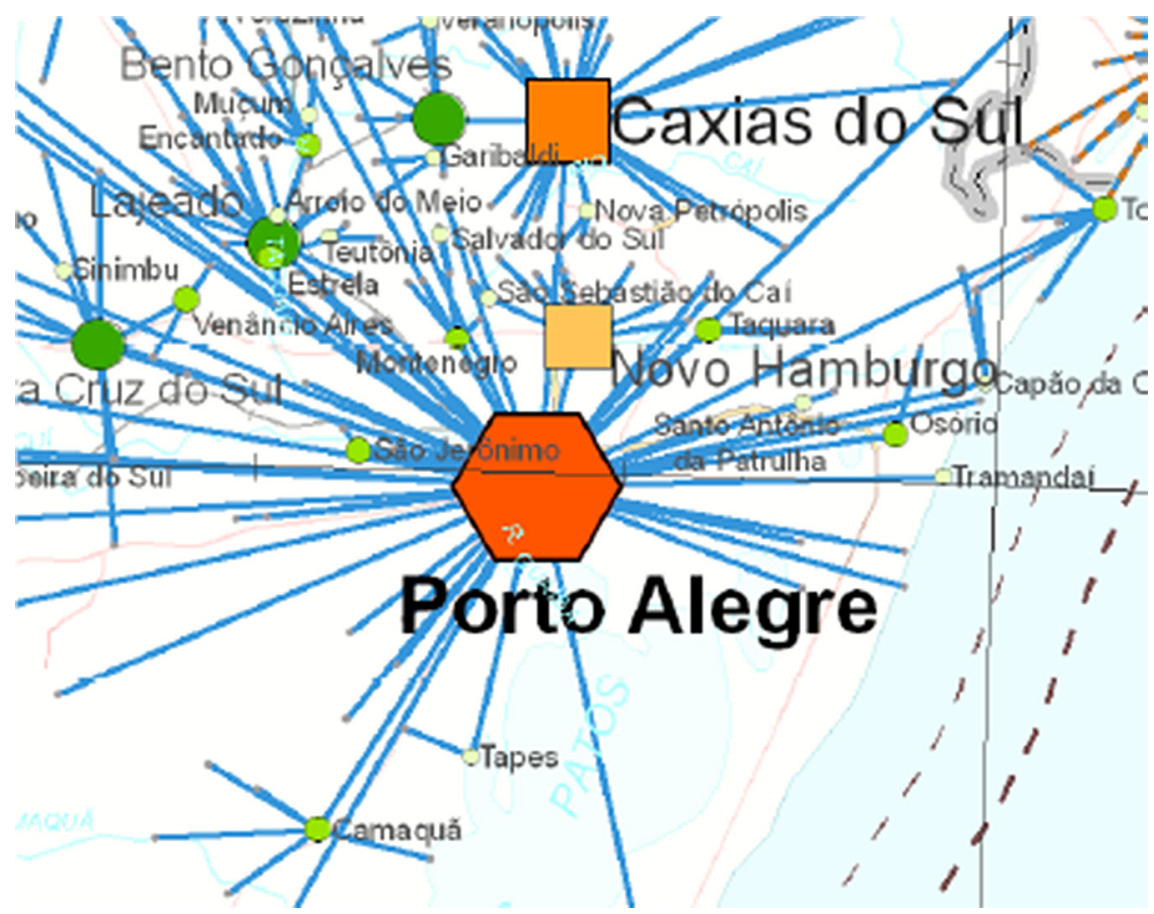

Fonte: IBGE (2008). 
As duas figuras confirmam o virtual processo de integração dessas aglomerações urbano-industriais.

\section{Metropolização e desenvolvimento regional}

Por fim, devemos falar do desenvolvimento regional e de sua relação com a metropolização. Nesse sentido, devemos pensar nos atores regionais e na sua relação com os processos que descrevemos e que balançam as hierarquias territoriais, mas também as hierarquias sociais tradicionais, ao introduzirem novos atores e uma nova racionalidade no processo de desenvolvimento regional. Santos ao abordar a região, nesse novo período, aponta que

[...] Acostumamo-nos a uma ideia de região como subespaço longamente elaborado, uma construção estável. Agora, nesse mundo globalizado, com a ampliação da divisão internacional do trabalho e 0 aumento exponencial do intercâmbio, dão-se, paralelamente, uma aceleração do movimento e mudanças mais repetidas, na forma e no conteúdo das regiões. [...] As condições atuais fazem com que as regiões se transformem continuamente, legando, portanto, uma menor duração ao edifício regional. Mas isso não suprime a região, apenas ela muda de conteúdo. A espessura do acontecer é aumentada, diante do maior volume de eventos por unidade de espaço e por unidade de tempo. A região continua a existir, mas com um nível de complexidade jamais visto pelo homem. (Santos, 1996, p. 166)

Esse nível de complexidade apontado por Santos, o maior volume de eventos e a menor rigidez e maior flexibilidade na constituição e permanência das regiões compõem uma nova realidade a ser considerada. A construção regional, antes de ser um artifício a priori, converte-se em um processo negociado e consensual entre os atores políticos, econômicos e sociais regionais.

Assim, baseados nas ideias do francês Paris (2004), podemos trilhar três caminhos de análise dos processos contemporâneos de metropolização com relação às aglomerações urbano-industriais: (1) a metropolização como a difusão regional da dinâmica metropolitana; (2) a metropolização como conexão dos espaços urbanos aos circuitos hegemônicos da economia globalizada; e (3) a metropolização mobilização de agentes políticos, econômicos e sociais regionais visando ao desenvolvimento regional conectado à economia metropolitana.

0 primeiro entende a metropolização como um processo espacial de difusão e concentração das condições gerais de produção (infraestruturas) para acumulação ou de difusão da dinâmica metropolitana sobre um território contíguo, o "espaço de metropolização" ou "em metropolização", que se amplia conformando as regiões urbanas que nos referíamos anteriormente. Nesse espaço, temos a submissão das atividades econômicas industriais, comerciais, de serviços e agrárias à lógica metropolitana, impactando fortemente nas atividades locais.

O segundo, do ponto de vista econômico, implica a relação do processo de metropolização com os modelos de desenvolvimento mais ou menos territorializados, podendo aproveitar das vantagens comparativas dos sistemas produtivos locais, ampliá-las a partir de circuitos de cooperação e inovação e conectá-las com 
a economia global ou, em um outro tipo de efeito, gerar "enclaves industriais" com alta tecnologia, mas com pouca ou quase nenhuma relação com as atividades locais.

0 terceiro trata da constituição política das aglomerações metropolitanas, quando os atores regionais em uma ação concertada "produzem a aglomeração" e (por que não?) a própria metropolização, em um processo de reescalonamento espacial ou territorial, conhecido como de "novo regionalismo". Ou seja, os atores regionais criam uma nova escala de poder e articulação regional, com o caráter e o alcance regional, mas profundamente relacionado com o metropolitano e o global, inserindo-se o mais soberanamente possível na lógica global.

Os três processos têm rebatimentos no desenvolvimento regional:

As aglomerações com melhor infraestrutura e mais conectadas à metrópole têm vantagens em um contexto de "guerra dos lugares" por empreendimentos e empregos, embora, muitas vezes, essa conexão signifique a destruição das economias locais tradicionais e a sua substituição por atores externos no controle da economia regional.

Os sistemas locais de produção podem (e devem) aproveitar-se das vantagens de proximidade com as metrópoles, especialmente dos seus serviços avançados, da concentração de atividades criativas, especialmente no que se refere à inovação tecnológica.

A aglomeração necessita da metrópole, dos serviços avançados da metrópole, mas pode ter o seu desenvolvimento autônomo e combinado com a metrópole. Pode estar conectada a outros espaços globais, mas também à metrópole.
Uma vez que as cadeias globais de valor que controlam o atual sistema produtivo mundial tendem a se organizar considerando o território local apenas como um recurso ou fator de produção, este pode sofrer com a desarticulação dos seus circuitos econômicos regionais ou locais, já que, em uma economia mundializada e financeirizada, o capital se despersonaliza, o controle acionário das empresas se dilui entre os acionistas invisíveis dos fundos de investimento e o balanço e a distribuição de dividendos assumem muito mais importância que o compromisso social e territorial da empresa (Halbert, 2016, p. 11).

Assim, segundo Halbert (ibid.), esses atores e suas regiões têm "duas opções" de inserção na economia global. Na primeira opção, prepara-se o território para a atração de agentes econômicos exógenos, em uma estratégia de atratividade e que insere a região em um "mercado de territórios' (Colletis apud ibid., p. 13). Na segunda, ativam-se recursos específicos do território (seu capital social e territorial) visando "sustentar a capacidade de combinar recursos locais e extralocais" (ibid., p. 18) e, com isso, manter certa autonomia na sua inserção global.

Os atores regionais devem estar preparados para conectar o desenvolvimento regional à economia global, um caminho (quase) sem volta e no qual os atores políticos, econômicos e sociais das regiões metropolitanas, aglomerações urbanas ou ainda dessas novas "regiões urbanas" devem ponderar as condições dessa conexão, de modo a promover ou garantir o bem-estar social da sua população, especialmente os mais vulneráveis à concorrência dos players globais.

As opções para essa inserção apontam diferentes caminhos e não se realizam sem 
embates e contradições, já que os atores regionais, ainda que os hegemônicos, frequentemente não compartilham da mesma visão e do mesmo projeto de desenvolvimento. Assim, dois caminhos principais se vislumbram: os que preconizam uma inserção subordinada e os que apontam para uma inserção mais soberana possível da região na globalização. Assim como os que projetam um modelo de desenvolvimento mais inclusivo e um modelo de desenvolvimento menos inclusivo dos setores de menor capital social da região no processo.

Uma última questão deve ser colocada sobre essa relação entre metropolização, aglomerações urbanas e desenvolvimento regional. Trata-se do "reescalonamento" da ação dos atores regionais, das suas escalas de atuação e da influência de outras escalas de ação, especialmente dos atores hegemônicos globais, sobre as estruturas regionais.
Se para o próprio Estado, com suas rígidas escalas, o momento atual é de crise e de dificuldades de pensar e operar em um contexto multiescalar, para as regiões, a tarefa não se coloca menos complexa. Assim, o que propomos aqui, neste ensaio, é a inserção de uma nova escala de ação, para além das escalas local, regional e metropolitana.

Ao pensarmos o desenvolvimento em uma região urbana que engloba a metrópole e as aglomerações urbano-industriais do entorno, estamos pensando em uma escala metropolitana estendida. E essa escala não está contemplada nos recortes institucionais disponíveis. A apreensão da complexidade dessa escala é mais um desafio que se coloca para os atores regionais, especialmente os das aglomerações, ainda fortemente pautados pelos limites institucionalizados, sejam eles estatais ou paraestatais.

\section{Paulo Roberto Rodrigues Soares}

Universidade Federal do Rio Grande do Sul, Departamento de Geografia, Programa de Pós-Graduação em Geografia. Porto Alegre, RS/Brasil.

paulo.soares@ufrgs.br 


\section{Notas}

(1) Esclarecemos que, ao longo deste trabalho, o termo irá se referir a um espaço densamente urbanizado sob o comando de uma ou mais metrópoles, sendo delimitado institucionalmente ou não. Nesse sentido, não estamos nos referimos e não é intenção deste trabalho debater a definição (ou as diversas definições) legal-institucional de região metropolitana.

(2) Neste artigo, estaremos nos referindo a metrópoles e regiões metropolitanas, considerando suas características gerais nas economias capitalistas industriais, tanto dos países centrais, como dos países periféricos, considerando, evidentemente, as diferenças entre os processos de metropolização em ambas as situações.

(3) Sobre os diversos conceitos e neologismos formulados para definir os espaços urbanos contemporâneos, ver Vicente Rufi (2003) e Soares (2008).

(4) Ver o artigo "Regiões metropolitanas ou aglomerações urbanas: contribuição para o debate no Rio Grande do Sul". Ensaios FEE 2015, v. 36, n. 2, pp. 323-342.

(5) Sobre a questão da escala urbano-regional e suas relações com a metropolização, ver o recente artigo de Moura (2016).

(6) As principais cidades médias desses estados conformam importantes aglomerações urbanoindustriais, tal como Londrina, Maringá, Ponta Grossa, Cascavel e Toledo (PR) e Joinville, Blumenau, Itajaí, Chapecó, Criciúma, Tubarão (SC).

(7) No Quadro 1, temos dados de regiões metropolitanas e aglomerações urbanas institucionalizadas (Região Metropolitana de Porto Alegre (RMPA), Região Metropolitana da Serra Gaúcha (RMSG), Aglomeração Urbana do Sul (Ausul) e aglomerações não institucionalizadas, delimitadas aqui a partir do estudo do IBGE (2015).

\section{Referências}

ASCHER, F. (2001). Les nouveaux principes de l'urbanisme. Paris, Editions l'Aube.

BENKO, G. e LIPIETZ, A. (1994). Las regiones que ganan. Districtos y redes: los nuevos paradigmas de la geografía económica. Valéncia, Edicions Alfons el Magnànim.

BRENNER, N. (2002). Decoding the newest 'Metropolitan Regionalism' in the USA: a critical overview. Cities, v. 19, n. 1, pp. 3-21.

CACCIARI, M. (2010). A cidade. Barcelona, Gustavo Gili.

CAMPOLINA-DINIZ, C. e CROCCO, M. A. (1996). Reestruturação econômica e impacto regional: o novo mapa da indústria brasileira. Nova Economia (UFMG). Belo Horizonte, v. 6, n.1, pp. 77-103.

DE MATTOS C. (2014). Gobernanza neoliberal, financiarización y metamorfosis urbana en el siglo XXI. Santiago de Chile, Instituto de Estudios Urbanos y Territoriales/PUC-Chile.

GUERRERO, G. A. e CONCEIÇÃO, C. S. (2011). Identificação e classificação das aglomerações produtivas e dos Arranjos Produtivos Locais no Estado do Rio Grande do Sul. Textos para Discussão FEE, n. 92. Porto Alegre, FEE. 
HALBERT, L. (2016). As duas opções metropolitanas das políticas de desenvolvimento territorial. Geographia. Niterói, ano 18, n. 36, pp. 10-25.

IBGE (2008). Diretoria de Geociências. Coordenação de grafia. Regiões de influência das cidades. 2007. Rio de Janeiro, IBGE.

(2014). Contas regionais do Brasil 2012. Rio de Janeiro, IBGE. (2015). Arranjos populacionais e concentrações urbanas no Brasil. Rio de Janeiro, IBGE.

INDOVINA, F. (2007). “La metropolización del território”. In: FONT, A. (ed.). La explosión de la ciudad: transformaciones territoriales en las regiones urbanas de la Europa meridional. Madri, Ministerio de Vivienda (España).

LEFEBVRE, H. (1972). La revolución urbana. Madri, Alianza Editorial.

LENCIONI, S. (2005). "Uma nova determinação do urbano: o desenvolvimento do processo de metropolização do espaço". In: CARLOS, A. F. A. et al. (orgs.). Dilemas urbanos: novas abordagens sobre a cidade. São Paulo, Contexto.

(2011). "Referências analíticas para a discussão da metamorfose metropolitana contemporânea". In: LENCIONI, S. et al. (orgs.). Transformações socioterritoriais nas metrópoles de Buenos Aires, São Paulo e Santiago. São Paulo, Paim.

(2013). "Metropolização do espaço: processos e dinâmicas". In: FERREIRA, A.; RUA, J.; MARAFON, G. J. e PINHEIRO DA SILVA, A. C. (orgs.). Metropolização do espaço. Gestão territorial e relações urbano-rurais. Rio de Janeiro, Consequência.

LEROY, S. (2000). Sémantiques de la métropolisation. L'Espace géographique. Paris, v. 29, n. 1, pp. 78-86.

MÉNDEZ, R. (2010). "La dimensión urbana del desarrollo territorial: significado actual de las ciudades de tamaño intermedio y las periferias metropolitanas". In: CORNEJO NIETO, C.; MORÁN SÁEZ, J. e PRADA TRIGO, J. (coords.). Ciudad, territorio y paisaje. Reflexiones para un debate multidisciplinar. Madrid, CSIC.

MONTEJANO ESCAMILLA, J. A. (2013). Nuevos procesos de metropolización del territorio. Espacialidades. Revista de temas contemporáneos sobre lugares, política y cultura. México, v. 3, n. 2, pp. 36-66.

MOURA, R. (2016). O complexo diálogo entre o urbano e o regional. Revista Brasileira de Desenvolvimento Regional. Blumenau, v. 4, n. 2, pp. 5-26.

PARIS, D. (2004). “Gouvernance des territoires, métropolisation et développment regional”. In : DOLEZ, B. e PARIS, D. Métropoles en construction. Territoires, politiques et processus. Paris, L'Harmattan.

PRADILLA-COBOS, E. (1998). Metrópolis y megalópolis en América Latina. Diseño y sociedad, n. 8, pp. 39-48.

PRADILLA-COBOS, E. e MÁRQUEZ LÓPEZ, L. (2007). Presente y futuro de las metrópolis de América Latina [1998]. Cadernos Metrópole. São Paulo, n. 18, pp. 173-206.

SANTOS, M. (1993). A urbanização brasileira. São Paulo, Hucitec.

(1996). A natureza do espaço. Técnica e tempo. Razão e emoção. São Paulo, Hucitec.

SASSEN, S. (1998). Ciudades en la economía global: enfoques teóricos y metodológicos. Eure. Santiago, v. XXIV, n. 71, pp. 5-25. 
SCOTT, A. J. (2014). Metrópole ressurgente: economia, sociedade e urbanização em um mundo interconectado. Geographia. Niterói, v. XVI, n. 14, pp. 8-37.

SCOTT, A. J.; STORPER, M.; AGNEW, J. e SOJA, E. (2001). Cidades-regiões globais. Espaço \& Debates. Revista de estudos urbanos e regionais. São Paulo, ano XVIII, n. 41, pp. 11-25.

SERRANO RODRÍGUEZ, A. (2003). El modelo territorial europeo: tendencias para el siglo XXI y sus implicaciones para el modelo territorial español. Urban. Madri, n. 8, pp. 35-54.

SILVEIRA, M. L. (2010). Região e globalização: pensando um esquema de análise. Redes. Santa Cruz do Sul, v. 15, n. 1, pp. 74-88.

SOARES, P. R. R. (2008) “Novas territorialidades e novos discursos sobre a dispersão e a concentração urbanas". In: HEIDRICH, A. et al. (orgs.). A emergência da multiterritorialidade. Porto Alegre, Editora da UFRGS.

SOARES, P. R. R. e SCHNEIDER, L. P. (2012). Notas sobre a desconcentração metropolitana no Rio Grande do Sul. Boletim Gaúcho de Geografia. Porto Alegre, v. 39, pp. 113-128.

SOARES, P. R. R. e FLORES, A. M. (2016). "As novas centralidades comerciais e de serviços na Região Metropolitana de Porto Alegre/RS, Brasil”. In: HEIDRICH, A. L.; SOARES, P. R. R.; TARTARUGA, I. G. P. e MAMARELLA, R. (orgs.). Estruturas e dinâmicas socioespaciais urbanas no Rio Grande no Sul: transformações em tempos de globalização (1991-2010). Porto Alegre, Letra 1.

SOJA, E. (2000). Post-metropolis. Critical studies of cities and regions. Oxford, Blackwell Publishers.

(2005). Algunas consideraciones sobre el concepto de ciudades región globales. Ekonomiaz Revista Vasca de Economía. Bilbao, n. 58, pp. 44-75.

(2013). Para além de postmetropolis. Revista UFMG. Belo Horizonte, v. 20, n. 1, pp.136-167.

SPOSITO, M. E. B. (2007). “Cidades médias: reestruturação das cidades e reestruturação urbana”. In: SPOSITO, M. E. B. (org.). Cidades médias: espaços em transição. São Paulo, Expressão Popular.

VELTZ, P. (1996). Mundialización, ciudades y territorios. La economía de archipiélago. Barcelona, Ariel.

VICENTE RUFI, F. (2003) ¿Nuevas palabras, nuevas ciudades? Revista de Geografía. Barcelona, n. 2, pp. $79-103$

Texto recebido em 7/ago/2017

Texto aprovado em 8/nov/2017 